\title{
EDITORIAL
}

\section{The fifth world symposium on pulmonary hypertension will REVEAL the impact of registries}

\section{Humbert}

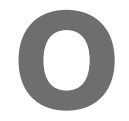

ne of the meanings of "reveal" is "to disclose through prophets". In the world of pulmonary arterial hypertension (PAH), REVEAL refers more modestly to the Registry to EValuate Early and Long-term PAH Disease Management [1-3]. In the current issue of the European Respiratory Review, two of the key contributors to this modern era registry have elegantly summarised their recent findings and future research plans [4].

The ability to identify and evaluate factors that affect survival in patients with $\mathrm{PAH}$ is of critical interest to clinicians. The first of several registries (Patient Registry for the Characterization of Primary Pulmonary Hypertension), supported by the National Institutes of Health (NIH) and the National Heart, Lung, and Blood Institute, was initiated in $1981[5,6]$. This registry enrolled patients with "primary pulmonary hypertension", a category that at the time included those with idiopathic, familial/heritable and drug/toxin-induced PAH [5]. Although shown to be a powerful tool for improving our understanding of $\mathrm{PAH}$, interpretations of data from the $\mathrm{NIH}$ registry are limited because of the era during which these data were collected (more than 20 yrs ago and, most importantly, prior to the availability of PAH therapies) [7-10]. Thus, a number of contemporary registries have been initiated worldwide to complement and update information from the pioneering NIH registry [1-4, 8-22], and data generated by these registries have been extremely helpful for investigators. As examples of the practical interest of such research, developing countries have produced high-quality data demonstrating the rapid progress of disease management in China $[19,20]$, and the specific causes and outcomes of PAH subsets in Brazil (where schistosomiasis remains a major burden) $[21,22]$. More recently, specific registries have studied other forms of pulmonary hypertension, such as chronic thromboembolic pulmonary hypertension, a major cause of pulmonary vascular disease that can be cured by pulmonary endarterectomy [23].

\footnotetext{
*Univ Paris-Sud, Faculté de Médecine, Kremlin-Bicêtre, " $A$ Assistance-Publique Hôpitaux de Paris, Service de Pneumologie et Réanimation Respiratoire, DHU Thorax Innovation (TORINO), Hôpital Antoine Béclère, Clamart, and "INSERM U999, LabEx LERMIT, Centre Chirurgical Marie Lannelongue, Le Plessis-Robinson, France.

CORRESPONDENCE: M. Humbert, Service de Pneumologie, Hôpital Antoine Béclère, 157 rue de la Porte de Trivaux, 92140 Clamart, France. E-mail: marc.humbert@abc.aphp.fr

PROVENANCE: Submitted article, peer reviewed.
}

We have come a long way since the early 1970s, when the World Health Organization sponsored the first international meeting in Geneva, Switzerland (October 15-17, 1973), on a mysterious condition named "primary pulmonary hypertension", spurred by the interest created by the sudden increase in the disease in patients who had used the anorexigen, aminorex fumarate [24]. Amazing achievements have been made in the field since then, as reflected by the World Pulmonary Hypertension conferences, which have taken place three more times since 1973 (Evian, France, September 6-10, 1998; Venice,

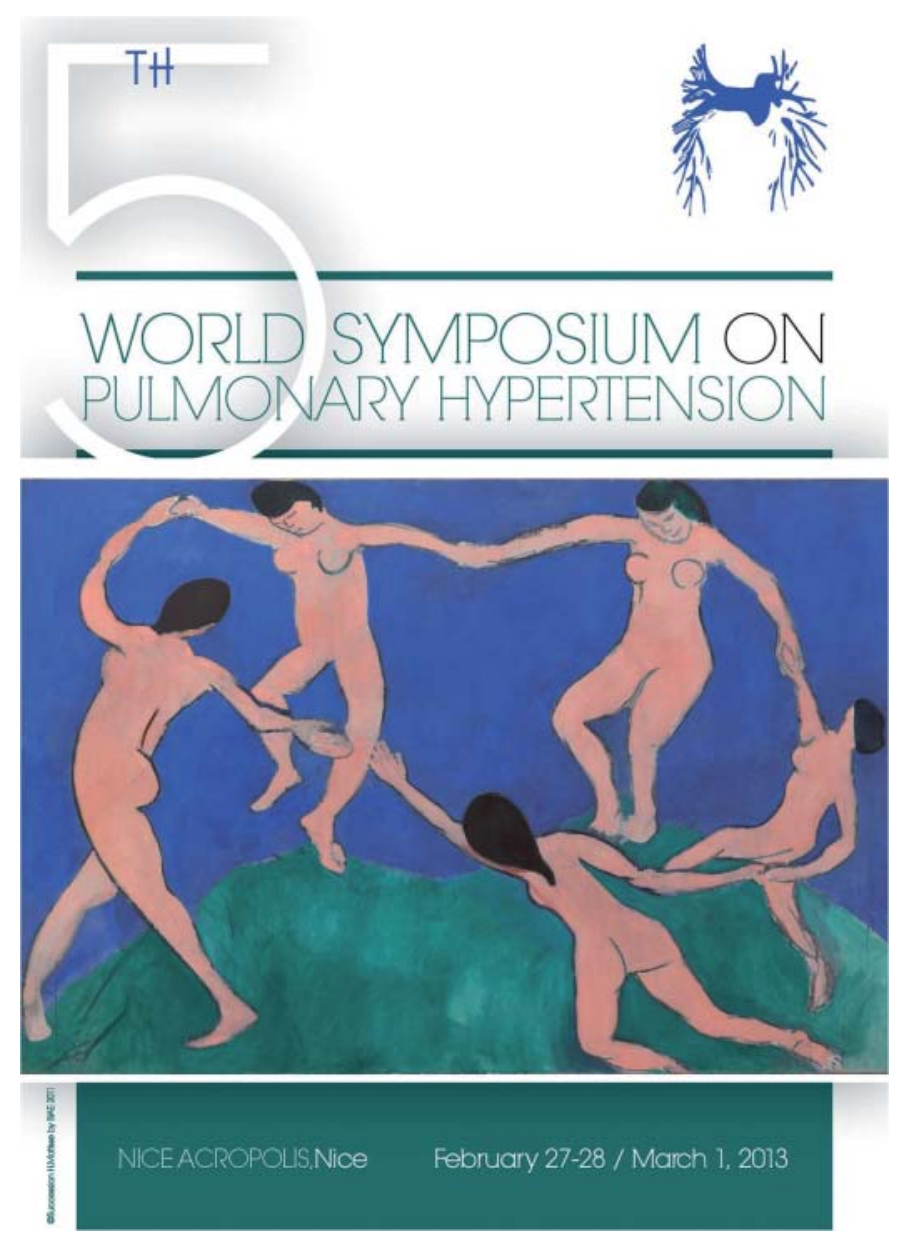

FIGURE 1. First announcement of the fifth world symposium on pulmonary hypertension (Nice, France, February 26 to March 1, 2013). 
Italy, June 23-25, 2003; and Dana Point, CA, USA, February $11-$ 14, 2008) [25]. The fifth world symposium on pulmonary hypertension will take place next year in Nice, France (February 26 to March 1, 2013) (fig. 1). The international symposium steering committee of 10 European and American specialists has identified 12 task forces which will review the whole spectrum of pulmonary hypertension basic and clinical science (www.wsph2013.com). In recognition of the critical importance of registries, a task force will be dedicated to examine the epidemiology of pulmonary hypertension with an emphasis on registries. Participants from nine developed and developing countries will represent European, US, Latin American and Chinese sites, where multicentre registries have already been implemented. The task force members will provide guidance on interpretation of current data and promotion of future research. Among key questions, the task force members will address the changing phenotypes in developing and developed countries as well as guidelines for registries implementation.

\section{STATEMENT OF INTEREST}

M. Humbert has relationships with drug companies including Actelion, AstraZeneca, Bayer, BMS, GSK, Merck, Novartis, Nycomed, Pfizer, Stallergènes, TEVA and United Therapeutics. In addition to being an investigator in trials involving these companies, relationships include consultancy service and membership of scientific advisory boards.

\section{REFERENCES}

1 McGoon MD, Krichman A, Farber HW, et al. Design of the REVEAL registry for US patients with pulmonary arterial hypertension. Mayo Clin Proc 2008; 83: 923-931.

2 Badesch DB, Raskob GE, Elliott CG, et al. Pulmonary arterial hypertension: baseline characteristics from the REVEAL Registry. Chest 2010; 137: 376-387.

3 Benza RL, Miller DP, Gomberg-Maitland M, et al. Predicting survival in pulmonary arterial hypertension: insights from the Registry to Evaluate Early and Long-Term Pulmonary Arterial Hypertension Disease Management (REVEAL). Circulation 2010; 122: 164-172.

4 McGoon MD, Miller DP. REVEAL: a contemporary US pulmonary arterial hypertension registry. Eur Respir Rev 2012; 21: 8-18.

5 Rich S, Dantzker DR, Ayres SM, et al. Primary pulmonary hypertension. A national prospective study. Ann Intern Med 1987; 107: 216-223.

6 D'Alonzo GE, Barst RJ, Ayres SM, et al. Survival in patients with primary pulmonary hypertension. Results from a national prospective registry. Ann Intern Med 1991; 115: 343-349.

7 Galiè N, Hoeper MM, Humbert M, et al. Guidelines for the diagnosis and treatment of pulmonary hypertension. Eur Respir $J$ 2009; 34: 1219-1263.
8 Frost AE, Badesch DB, Barst RJ, et al. The changing picture of patients with pulmonary arterial hypertension in the United States: how REVEAL differs from historic and non-US contemporary registries. Chest 2011; 139: 128-137.

9 McLaughlin VV, Suissa S. Prognosis of pulmonary arterial hypertension: the power of clinical registries of rare diseases. Circulation 2010; 122: 106-108.

10 Jardim C, Hoette S, Souza R. Contemporary issues in pulmonary hypertension. Eur Respir Rev 2010; 19: 266-271.

11 Humbert M, Sitbon O, Chaouat A, et al. Pulmonary arterial hypertension in France: results from a national registry. Am J Respir Crit Care Med 2006; 173: 1023-1030.

12 Peacock AJ, Murphy NF, McMurray JJ, et al. An epidemiological study of pulmonary arterial hypertension. Eur Respir J 2007; 30: 104-109.

13 Fasnacht MS, Tolsa JF, Beghetti M. The Swiss registry for pulmonary arterial hypertension: the paediatric experience. Swiss Med Wkly 2007; 137: 510-513.

14 Thenappan T, Shah SJ, Rich S, et al. A USA-based registry for pulmonary arterial hypertension: 1982-2006. Eur Respir J 2007; 30: 1103-1110.

15 Humbert M, Sitbon O, Yaici A, et al. Survival in incident and prevalent cohorts of patients with pulmonary arterial hypertension. Eur Respir J 2010; 36: 549-555.

16 Humbert M, Sitbon O, Chaouat A, et al. Survival in patients with idiopathic, familial, and anorexigen-associated pulmonary arterial hypertension in the modern management era. Circulation 2010; 122: $156-163$.

17 Thenappan T, Shah SJ, Rich S, et al. Survival in pulmonary arterial hypertension: a reappraisal of the NIH risk stratification equation. Eur Respir J 2010; 35: 1079-1087.

18 Kane GC, Maradit-Kremers H, Slusser JP, et al. Integration of clinical and hemodynamic parameters in the prediction of longterm survival in patients with pulmonary arterial hypertension. Chest 2011; 139: 1285-1293.

19 Jing $Z C, X u X Q$, Han $Z Y$, et al. Registry and survival study in Chinese patients with idiopathic and familial pulmonary arterial hypertension. Chest 2007; 132: 373-379.

20 Zhang R, Dai LZ, Xie WP, et al. Survival of chinese patients with pulmonary arterial hypertension in the modern management era. Chest 2011; 140: 301-309.

21 Lapa M, Dias B, Jardim C, et al. Cardio-pulmonary manifestations of hepatosplenic schistosomiasis. Circulation 2009; 119: 1518-1523.

22 Dos Santos Fernandes CJ, Jardim CVP, Hovnanian A, et al. Survival in schistosomiasis-associated pulmonary arterial hypertension. J Am Coll Cardiol 2010; 56: 715-720.

23 Pepke-Zaba J, Delcroix M, Lang I, et al. Chronic thromboembolic pulmonary hypertension (CTEPH): results from an international prospective registry. Circulation 2011; 124: 1973-1981.

24 Gurtner HP. Pulmonary hypertension, "plexogenic pulmonary arteriopathy" and the appetite depressant drug aminorex: post or propter? Bull Europ Physiopath Resp 1979; 15: 897-923.

25 Humbert M, McLaughlin VV. The 4th world symposium on pulmonary hypertension. J Am Coll Cardiol 2009; 54: Suppl. 1, S1-S2. 